normal, and again in others the profile may remain straight in biting (as in Fig. 2). As far as I could observe in Tarantola, the upper jaw was always raised in opening the mouth, and the profile of the head straightened from its normal curve when at rest, but on closing the mouth in biting the movement of the upper jaw depended upon the relative position of the animal to the object which it was biting. This depression of the upper jaw may be also often witnessed when the mouth is closed, and it may be produced by applying slight pressure to the head. The animal seems to make the most of its powers of expression, for on provocation it opens its relatively huge mouth with the greatest readiness, and will keep it open for a considerable time, during which its appearance is sufficiently awe-inspiring. The fact that the anterior part of the skull is not co-ossified with the posterior part is well known. Thus in Huxley's " Anatomy of Vertebrata" (I871, p. 225) the following statement is made concerning the geckos: "Neither the upper nor the lower temporal arcades are ossified, the post-frontal being connected with the squamosal and the maxilla with the quadrateby ligament ;" and Mr. Boulenger informs me that had he been asked whether the upper jaw of such lizards is moved in biting, he would have been inclined to answer in the affirmative, reasoning from the well-known condition of the skull. But I believe it has not been hitherto actually observed that such movable articulations possess a functional value in the living animal, and that the geckos must be added to the well-known instance of the parrots as Vertebrata which move the upper jaw in biting. It is extremely probable that the same observations will be found to hold for other families of lizards.

Wykeham House, Oxford, March I

\section{Weight and Mass}

TILl some quite new facts are discovered, such as shall force us to reconsider our convictions (which have not been lightly formed), I do not think it profitable to accept a quasi-metaphysical challenge from my friend Prof. Greenhill. He has at heart, as strongly as I have, the cause of definiteness and accu racy:- and if he, as is natural for one in his position, feels inclined to sympathise with the "vernacular" of Engineers rather than object to it as I do, there is nothing for it but to agree to differ. My remarks on this aspect of the subject were of the most cursory and general character ; and I went so far as to say that, as the book in question was written by a practical man for practical men, "perhaps we ought not to complain."

I cannot, however, go so much further as to allow, with Prof Greenhill, that it is "perfectly correct" to use the words pound or ton "side by side in two senses." As regards this practice $\mathrm{I}$, in turn, must quote from an unpublished letter of ClerkMaxwell's. [The passage purports to be part of a (reported) speech by a well-known Evolutionist.]

"He regretted that so many..." were in the habit of employing the word in a sense too definite and limited to be of any use in a complete theory..... He had himself always been careful to preserve that largeness of meaning which was too often lost sight of in elementary works. This was best done by using the word sometimes in one sense and sometimes in another; and in this way he trusted he had made the word occupy a sufficiently large field of thought."

I have three other remarks to make upon Prof. Greenhill's letter :-

(I) He shows the absurdity of defining the weight of a body as "the force with which it is attracted by the earth." Of course such a definition must necessarily be absurd provided it comes after an explanation (given by Prof. Greenhill) that "weight" is to be understood in the sense of "mass." But from this explanation itself it would unfortunately follow that $a$ body has weight even when it is no longer heavy; as, for instance, when it is in a (supposed) cavity at the centre of the earth! Prof. Greenhill says that "weight" is " used in ordinary language in most cases " in the same sense as "mass." Surely the great majority of men regard weight from the point of view of the sublime Porthos:-

"Ma vaisselle d'argent . . . . qui doit peser de mille à douze cents livres, $\mathrm{CAR}$ je pouvais à grande peine soulever le coffre qui la renferme, et ne faisais que six fois le tour de ma chambre en le portant."

(2) He also speals of certain difficulties imposed by the "rules of language." I do not ascribe to them so lofty an origin. They are the offspring of the dogmatic ignorance which has peopled the realms of science with Centrifugal Force and its fellow monsters.

(3) $\mathrm{He}$ has commented solely on a passing remark in my article, and says nothing as to its main purpose. I hope, however, that he will eschew "statical" measures of force, and give his hearty aid as well as his good wishes in the war of extermination which must perpetually be waged against the too luxuriant undergrowth of the scientific garden:- the circlesquarers, the perpetual-motionists, and (in the case before us) the measurers of potential energy in terms of horse-power.

P. G. T.

An Error in Maxwell's "Electricity and Magnetism"

IT may be allowed to me to remark that the error mentioned on pp. 172 and 223 of NATURE has its origin really in Helmholtz's renowned paper ("Ueber die Erhaltung der Kraft," I 847, p. 67), and that it thence found its way into most of the textbooks on electricity. It has sometimes been detected and hinted at ; for the first time, I believe, in C. Neumann's paper published in the Ber. d. k. sächs. Ges. d. Wiss, at Leipzig (187I), "Elektrodynamische Untersuchungen mit besonderer Rücksicht auf das Princip der Energie." There we find (p. 436) the formula-

$$
T \nabla+T_{1} \nabla_{1}=T^{2} w+T_{1}{ }^{2} w_{1}-T T_{1} \frac{d V_{01}}{d t}+\frac{d F}{d t},
$$

which is identical with the equation of energy given in NATURE, p. 223, if we put-

$$
\nabla_{1}=A_{1}, w_{1}=R_{1},-T T_{1} V_{01}=T_{m}, F=T_{e}, \& c .
$$

The formula is followed by the remark that it agrees entirely with the formula given by Helmholtz, the only difference being the last term $\frac{d F}{d t}$, which in the latter is wanting; thus we may say that by Helmholtz the potential energy of the system invariably is expressed by zero.

Being formerly unaware of Neumann's researches, 1, by another way, came to the same results, see the paper "Das Princip der Energie in seiner Anwendung auf die ponderomotorischen und elektromotorischen Wirkungen des elektrischen Stromes," published in the Sitzber. d. k. böhm. Ges. d. Wiss, (vide NATURE, vol, xxxii. p. 308). In this paper I have hinted at one probable cause of this and similar mistakes and their relatively difficult discovery, of which the repetition of the error in the best text-books is a decisive proof. This cause I believe to be the trivial circumstance that there is no consistent and generally accepted notation of the different forms of potential and energy. This renders the comparison of different writings on this subject sometimes quite perplexing. When, for example, two authors denote the same thing, the one by $V$, the other by $-V$, and when the first writes the expression $d\left(T_{1} T_{2} V\right)$ in the form-$$
\text { the other the identical expression }-d\left(T_{1} T_{2} V\right) \text { in the form- }
$$$$
T_{1} T_{2} d V-T_{2} d\left(T_{1} V\right)-T_{1} d\left(T_{2} V\right)
$$

it may happen that they themselves and also other readers overlook the difference of sign, and that they continue to reason as if their $\mathrm{V}$ were identical. Such mistakes occur oftener than is supposed. See the interesting note at the end of Sir William Thomson's paper on "Capillary Attraction," NATURE, vol. xxxiv. p. 369 .

Could there not be found a means of avoiding the inconveniences caused by such mistakes and the loss of labour spent in detecting them? I dare not hint at the possibility of an international system of notations of the most important physical quantities; thoroughly consistent, and recommended by the highest scientific authorities; for the realisation of such a system would probably meet difficulties quite insurmountable.

Prague University, March I2

A. Seydler

\section{Tabasheer}

Mr. Dyer in his article on "Tabasheer" in NATURE of February 24 (p. 396), throws out the suggestion that the silica deposited in the joints of bamboo may have undergone a process of dialysis. It may be of some interest to him, and to your readers generally, to learn that plates of transparent compact silica, $\mathrm{SiO}_{2}$ may be formed by dialysing the basic soda silicate. Four or 